\title{
Bioethics, the global church, and family planning
}

\section{Michael J. Sleasman ${ }^{a}$, Paige Comstock Cunningham ${ }^{\text {b }}$}

\author{
${ }^{a}$ PhD, Managing Director \& Research Scholar, The Center for Bioethics \& Human Dignity, Affiliate Professor of \\ Bioethics, Trinity International University, USA \\ ${ }^{b}$ JD, PhD, Executive Director, The Center for Bioethics \& Human Dignity, Affiliate professor at Trinity Law School \\ and Trinity Graduate School, Trinity International University, USA
}

The Center for Bioethics \& Human Dignity (CBHD) was pleased to be invited to collaborate with the Christian Journal for Global Health in the call for a themed issue on "The Global Church and Family Planning," papers from which were to be jointly published in our respective publications. Despite the significant progress made through the Millennium Development Goals (MDGs) and the subsequent adoption of the Sustainable Development Goals (SDGs), maternal and infant mortality remains unacceptably high in certain parts of the world. The work of aid organizations to decrease such tragedies in global health is laudable, and many faith-based organizations (FBOs) are at the forefront of commendable efforts in this regard.

Part of the purpose of this themed issue was to raise particular ethical and theological questions surrounding the practice of family planning and its relationship to these broader efforts to reduce maternal and infant mortality, particularly within the context of faith-based organizations. Embedded in the broad international discussions of family planning is the assumption that there is an "unmet need" for contraception, a concept which is regularly promoted within international health organizations such as the United Nations Population Fund. What is lacking is an awareness that this terminology implicitly makes ethical claims about contraception, procreation, and sexuality. For example, one of the criticisms about "unmet need" made in a previous paper is that it assumes that if a woman is not currently using contraception, regardless of her reason, she has an "unmet need." This assumption might imply an ethical obligation to use contraception throughout one's childbearing years to avoid having an unacceptably high number of children. ${ }^{2}$

Thus, it was of particular interest to CBHD to address questions concerning family planning and the global Church in light of Christian bioethical and/or Christian bioethical resources that could be brought to bear on the conversation. How might these resources guide the Church's response to these questions as well as the work of confessionally-oriented FBOs?

Furthermore, questions remain that are germane to Christians within the aid work and global health communities. Are concepts and practices derived within the context of international health organizations adequately examined for assumptions or latent agendas that may be in conflict with or even antagonistic to Christian ethical and theological commitments regarding the beginning of life, abortion, marriage, sexuality, and procreation? What are the explicit and implicit assumptions of the relationship, if any, of family planning and birth spacing to contraception and abortion within the broader international health context, and for Christian FBOs in particular? How does natural family planning fit within both international and Christian conversations, in light of significant Christian ecclesial traditions' long- 
standing and well-articulated resistance to contraception, and the even broader Christian rejection of abortive practices?

The international conversation around family planning methods skews toward provision of "modern contraceptives," access to "safe abortion," and the appropriate spacing of children. Yet, natural family planning such as fertility awareness based methods, which may have success rates as high as many "modern methods" both for avoiding and achieving pregnancy, is excluded from assessment and recommendation because it is categorized as a "traditional method." "3,4 Tension also arises over the vigorously disputed relationship between contraceptive use and reduced incidence of abortion. Much of the data regarding maternal mortality, including from induced abortion, is based upon estimates. Conclusions about these matters all too often depend upon the particular goal of the researchers or the funders of the study.

CBHD's interest also has been to foster greater awareness of the issues in global health, particularly women's health, within the context of Christian bioethics and to promote the ethical engagement of the Church on a set of important social issues. Of special interest was fostering awareness of the needs and issues to address, and to assist in initiating a conversation within local churches, who are seen as a key factor in encouraging uptake of family planning services. We would encourage not only scholars and clinicians, but also pastors to engage such issues in global health, and specifically maternal and infant mortality in an informed manner thoroughly rooted in their biblical and theological convictions. How do we balance biblical notions of children as blessings and gifts from God with the stark realities of starvation? How do we balance biblical commitments to the sacred relationship between a husband and wife, and the realities that many pregnancies occur outside this relationship, within abusive or coercive relationships, under the duress of poverty, or at a time the parents do not desire? Is it appropriate to introduce biblical stewardship in the conversation regarding family size?

We were dismayed at the lack of response from the bioethics community to the initial call for papers, as we had hoped for a robust Christian bioethical analysis of these profoundly important questions. $^{10}$ Most of the accepted papers were drawn from the public and global health communities. These, naturally, presented operational models of family planning as implemented by FBOs. The papers described a variety of practical challenges, such as unavailability of drugs, increasing community awareness about family planning services, and the lack of involvement of faith leaders. In some cases, model programs were discussed, while others provided empirical analysis of practices and attitudes. ${ }^{11-17}$ Each advocated, to greater or lesser degrees, for the expansion of family planning services and solutions. Given their focus on operational concerns, for the most part these papers did not examine the theological or ethical justifications for expansion. Nor did they place these practices within a broader theological and ethical framework of the Christian life, marriage, sexuality, and procreation. While such discussions may have been understandably bypassed, many of them nonetheless uncritically accepted and used the language of family planning and "unmet need" that make implicit assumptions about such broader framework concerns.

It must be recognized of course that such considerations are generally beyond the scope of papers focused on operational concerns and empirical analysis of best practices, and perhaps beyond the expertise of the contributors. Nonetheless, the absence of substantive Christian analysis illustrates an apparent divide, even if not done so intentionally, between scholarship in the Christian public health and global health literature, and the relevant scholarship in theology and Christian (bio)ethics. ${ }^{18}$ Is this division evidence of 
a mutual hermeneutic of suspicion about underlying assumptions?

We are genuinely grateful, and even more so given that there was not a more robust response from the broader Christian bioethics community, for the contributions of Rebecca Oas and Monique and Jeffrey Wubbenhorst in their respective editorials and commentaries for raising important questions and issues for future consideration and discourse. Oas's editorial questions the legitimacy of the assumed existence of a broadly "unmet need." Oas raises important areas of concern specifically for those who are firmly located within the theological and ethical commitments of the Roman Catholic tradition, but also those from other ecclesial traditions that share prolife convictions and a concern for the promotion of marriage and family. In this volume, Wubbenhorst and Wubbenhorst, likewise, raise a variety of considerations from an evangelical perspective, many of which would be applicable across the broad spectrum of confessional Christianity. ${ }^{19}$ They provide important background materials to contextualize the discussion, including the historical reception of contraceptive practices within the various Christian traditions, as well as the international health context in which contemporary discourse about family planning occurs. They conclude with a pointed set of convictions which they argue all confessionally-oriented FBOs and church-based ministries should uphold. Perhaps most controversially, Wubbenhorst and Wubbenhorst challenge the assumption that family planning is the best approach for reducing maternal and infant mortality, questioning several of the underlying claims and assumptions on theological grounds, as well as pointing to disagreements in the medical and social science literature regarding the impact and health benefits of birth spacing and claims surrounding unmet need and population health.

As relative newcomers to this conversation, CBHD does not have a particular stake in individual perspectives and does not take a formal position on the issue of family planning (when not associated with abortion). Indeed, even between the present two authors of this editorial there is not complete agreement about the use of contraception and the appropriate role for churches in advocating family planning practices. However, as a Christian bioethics research center, there are several points of contention that we believe are essential to address if there is to be any hope for robust engagement on these issues.

The first is the use of language, particularly when many of the terms utilized within discussions of a given controversy have emerged within valueladen and ideologically charged contexts. This does not mean that terms must be abandoned, but philosophical precision becomes a necessity. One FBO may use a definition to avoid conceptual baggage, yet colleagues or other FBOs do not find the definition persuasive or indicative that underlying problems do not exist. Furthermore, bioethics has demonstrated time and again that terms often become proxies for politicized discourse and can be employed to obfuscate deeply held assumptions or to sway public opinion. Those familiar with prolife controversies easily recognize the obfuscation triggered by separating fertilization as the beginning of an individual human life vs. implantation as the beginning of pregnancy. On the other hand, linking abortion with all contraception as an instance of the "contraceptive mentality" is equally problematic. Another example of terminological disputes for rhetorical rationale occurs in end-of-life ethics with the various uses of euthanasia, physician-assisted suicide, aid in dying, and dignity in dying. We suggest greater methodological self-awareness be directed to the ways in which Christians utilize terminology in the discourse of family planning.

A second area of contention arises at the limits of medical and scientific research and the challenge of data and studies that appear to be in conflict. The purpose of a study may influence not 
only what is studied, but also the stated outcomes and conclusions. For example, studies on the maternal mortality ratio (MMR) as a major indicator of public health have been critiqued for shifting their emphasis to numbers, perhaps to satisfy business-oriented private donors who have inordinate influence, and away from attention to social justice, to national health information systems, and to other factors that affect maternal health. ${ }^{20}$ Tensions about how studies are designed raise a more fundamental question - whether family planning actually achieves the very thing it purports to do. Does family planning actually reduce the risk of maternal and infant mortality? It clearly reduces the number of pregnancies, but do such interventions actually result in safer pregnancies? It depends on what is being assessed, and how. More work needs to be done to demonstrate clear evidence in this regard.

A third area arises particularly within Protestant ecclesial contexts, but increasingly among the laity within Orthodox and Catholic traditions as well, and that is the lack of a theologically robust and ethically consistent view of marriage, sexuality, procreation, and the appropriate role of technology to facilitate, assist, or hinder procreation. These concerns go well beyond a discussion of family planning to include consideration of the wide range of contraceptive practices as such, the use of the spectrum of assisted reproductive and fertility interventions, and the increasingly common use of a variety of reprogenetic technologies in the procreative process. The inability of many Christians to identify these as more than merely medical decisions that require substantive theological and moral consideration portends broader concerns that the church will not be equipped to adequately engage biotechnologies and other emerging technologies with distinctly Christian commitments and values. Perhaps more sobering is that even where orthodoxy is taught and known, orthopraxis does not necessarily follow. At a recent colloquium hosted by CBHD, Eastern Orthodox, Roman Catholic, and evangelical scholars admitted that their congregations often choose a utilitarian path of avoiding or obtaining a child of one's own at any cost with little regard to pastoral guidance or the moral pronouncements of the Church.

We pose these not as contentions with any of the specific papers in this themed issue, but rather as a collegial challenge for others to take up these issues and bring greater clarity to a discourse about the global church and family planning. We do so not with a naïve expectation that universal agreement will be reached. Indeed, some of the disagreements seem intractable, particularly some of the differences between those working in public and global health vs. those within prolife advocacy contexts regarding partnership with international health organizations that promote abortion. These issues aside, we believe that all sides will benefit from more thoughtful engagement, and hope that conversation initiated in this themed issue will foster a more robust dialogue in years to come. Even more to be desired is a greater unity about the obligation for all Christians to engage theologically and reflectively with all the technologies that threaten respect for persons and that undermine our common human flourishing.

\section{References}

1. Oas R. Communities of faith and the global family planning movement: friends or foes? Christian Journal for Global Health 2017; 4(2):3-9. https://doi.org/10.15566/cjgh.v4i2.183

2. See, e.g., the discussion between philosophers Travis Rieder and Rebecca Kukla, As environmental catastrophe looms, is it ethical to have children? Foreign Policy, May 31, 2017. Available from: http://foreignpolicy.com/2017/05/31/is-it-ethical-tohave-children-climate-change-family-planning/

3. Frank-Herrmann P et al. The effectiveness of a fertility awareness based method to avoid pregnancy in relation to a couple's sexual behaviour during the fertile time: a prospective longitudinal study. Human Reproduction 2007; 22(5):1310-319. 
https://doi.org/10.1093/humrep/dem003

4. Frank-Hermann $P$ et al. Natural family planning with and without barrier method use in the fertile phase: efficacy in relation to sexual behavior: a German prospective long-term study. Advances in Contraception 1997; 13(2-3):179-189. https://doi.org/10.1023/A:1006551921219

5. Malarcher JS et al. Fertility awareness methods: distinctive modern contraceptives. Global Health: Science and Practice 2016; 4(1):13-15. http://dx.doi.org/10.9745/GHSP-D-15-00297

6. Malarcher JS et al. Response to Austad: offering a range of methods, including fertility awareness methods, facilitates method choice. Global Health: Science and Practice 2016; 4(2):346-349. http://dx.doi.org/10.9745/GHSP-D-16-00115.

7. For a comprehensive review, see Manhart MD et al. Fertility awareness-based methods of family planning: a review of effectiveness for avoiding pregnancy using SORT. Osteopathic Family Physician 2013; 5(1): 2-8.

https://doi.org/10.1016/j.osfp.2012.09.002

8. But see also this concern about women's sexual agency, and the definition of "modern methods" as designed to "overcome biology." Austad K et al. Fertility awareness methods are not modern contraceptives: defining contraception to reflect our priorities. Global Health: Science and Practice 2016; 4(2):342-345. https://doi.org/10.9745/GHSP-D-1600044

9. Malarcher JS et al. Fertility awareness methods, 1315. Further, inclusion of fertility awareness methods as modern contraceptives is "the technical position of the Office of Population and Reproductive Health of the United States Agency for International Development." Malarcher et al., 13.

10. The Center for Bioethics \& Human Dignity aggressively promoted the call for papers. Despite nearly 3,000 views from our constituents, no proposals were submitted. In response, we personally invited scholars to contribute.

11. Otchere $\mathrm{S}$ et al. Social accountability and education revives auxiliary nurse-midwife sub-centers in India, reduces travel time and increases access to family planning services. Christian Journal for Global Health 2017; 4(2):10-18. https://doi.org/10.15566/cjgh.v4i2.177
12. Metger A and Bormet M. Pharmaceutical stockouts: problems and remedies for faith-based health facilities in Africa. Christian Journal for Global Health 2017; 4(2):19-29. https://doi.org/10.15566/cjgh.v4i2.130

13. Ghanshyam KB et al. The increasing access to family planning services through a non-health sector: Technical Integration Coverage and Access (TICA) in Nepal. Christian Journal for Global Health 2017; 4(2):30-42. https://doi.org/10.15566/cjgh.v4i2.170

14. Vanenk L et al. Closing the gap: the potential of Christian Health Associations in expanding access to family planning. Christian Journal for Global Health 2017; 4(2):53-65. https://doi.org/10.15566/cjgh.v4i2.164

15. Alikali M. The attitudes and activities of pastors and faith leaders in Zimbabwe on the use of family planning methods among their members. Christian Journal for Global Health 2017; 4(2):66-74. https://doi.org/10.15566/cigh.v4i2.188

16. Allison A and Basikoro E. Why World Vision supports healthy timing and spacing of pregnancies to improve maternal and child health: a faith-based perspective. Christian Journal for Global Health 2017; 4(2):75-79. https://doi.org/10.15566/cjgh.v4i2.169

17. Duah J and Yeboah P. Christian Journal for Global Health 2017; 4(2):80-86; Docking ML. Increasing the church's relevance and impact in poor-resource areas by adding sexual reproductive health to missional activities. Christian Journal for Global Health 2017; 4(2):95-99. https://doi.org/10.15566/cjgh.v4i2.175

18. An historical example may illustrate this tension. Pope Benedict XVI was widely criticized by the HIV/AIDS and public health communities for his observation that the strategy to reduce HIV/AIDS in Africa via promoting condom use "aggravates" the problem. Pisa N. Anger as Pope Benedict XVI says Condoms Make AIDS Worse, The Telegraph, March 17, 2009. Available from: http://www.telegraph.co.uk/news/worldnews/africaa ndindianocean/cameroon/5007124/Anger-as-PopeBenedict-XVI-says-condoms-make-Aidsworse.html. He focused on the effectiveness and morally preferable behavioral change. A leading HIV/AIDS researcher eventually concluded that the Pope was correct: Green E. Condoms, HIV-AIDS

Nov 2017. Christian Journal for Global Health 4(3):6-11. 
and Africa - the Pope was right. Washington Post, March 29, 2009.

http://www.washingtonpost.com/wpdyn/content/article/2009/03/27/AR2009032702825. $\underline{\mathrm{html}}$

19. Wubbenhorst M and Wubbenhorst J. Should Evangelical Christian organizations support international family planning? Christian Journal for
Global Health 2017; 4(3):20-38. https://doi.org/10.15566/cjgh.v4i3.184

20. Storeng KT and Béhague DP. "Guilty until proven innocent": the contested use of maternal mortality indicators in global health. Critical Public Health 2017; 2:163-176.

https://doi.org/10.1080/09581596.2016.1259459

Competing Interests: None declared.

Correspondence: Michael J Sleasman, msleasman@cbhd.org and Paige Comstock Cunningham, pcunningham@cbhd.org The Center for Bioethics \& Human Dignity, https://cbhd.org

Cite this article as: Sleasman MJ, Cunningham PC. Bioethics, the global church, and family planning. Christian Journal for Global Health. Nov 2017; 4(3):6-11. https://doi.org/10.15566/cjgh.v4i3.203

(C) Sleasman MJ, Cunningham PC. This is an open-access article distributed under the terms of the Creative Commons Attribution License, which permits unrestricted use, distribution, and reproduction in any medium, provided the original author and source are properly cited. To view a copy of the license, visit https://creativecommons.org/licenses/by/4.0/

$$
\text { www.cjgh.org }
$$

